SEXUAL BEHAVIOUR

\title{
Associations between the sexual behaviour of men who have sex with men and the structure and composition of their social networks
}

\author{
A M A Smith, J Grierson, D Wain, M Pitts, P Pattison
}

Sex Transm Infect 2004;80:455-458. doi: 10.1136/sti.2004.010355

See end of article for authors' affiliations

Correspondence to:

Correspondence to:
Anthony Smith, Australian Research Centre in Sex,

Health and Society, La

Trobe University, 215

Franklin Street,

Melbourne, Victoria 3000,

Australia; anthony.smith@

latrobe.edu.au

Accepted for publication 30 June 2004
Objective: This exploratory study identified associations between the number of sexual partners reported by men who have sex with men (MSM) and the structure and composition of their social networks. Methods: A cross sectional survey was conducted of men recruited as key informants, through advertising and chain referral. A face to face interview was conducted with 206 MSM. The interview included information on the number of sexual partners in the previous year and sociodemographic and behavioural characteristics of the participant. Social networks were enumerated and network size and density were calculated. Ordered logistic regression was used to assess the associations between number of sexual partners and personal and network characteristics.

Results: The number of anal sex partners reported was higher if the participant had injected drugs in the past year rather than never having injected (odds ratio, 95\% confidence interval: $3.23,1.28$ to 8.15), decreased with network density $(0.014,0.002$ to 0.008$)$ and increased if the network did not comprise only HIV negative people (1.77, 1.05 to 2.99$)$. The number of additional oral sex partners increased with network size $(1.06,1.02$ to 1.10$)$ and decreased with increased network density $(0.034,0.006$ to 0.205$)$. In addition to similar effects of network size $(1.05,1.01$ to 1.09$)$ and network density $(0.086,0.013$ to $0.563)$ the model for the number of additional manual sex partners also included age $(1.03,1.01$ to 1.05).

Conclusion: The density of the social networks of MSM appears strongly and consistently associated with patterns of sexual behaviour. This underlines the importance of using network approaches to understanding the sexual behaviour of MSM and their potential value in identifying novel strategies for intervention.
$\mathrm{T}$ he composition and structure of the social networks of injecting drug users (IDU) have been found in a number of studies to be implicated in the sexual and drug use risk behaviours of IDU. ${ }^{2}$ To date, the social networks of MSM have been the subject of little research. One study found that having network members who were diagnosed with AIDS was associated with lower rates of unsafe sex. ${ }^{3}$ Beyond that finding, it is not known whether the composition and structure of the social networks of MSM are associated with sexual behaviour. The purpose of the present report is to explore associations between the number of sexual partners MSM report and the structure and composition of their social networks.

\section{METHODS}

\section{Study sample}

During 2002 we recruited 206 homosexual and bisexual men. Five were key informants (2.4\%), 77 were recruited through chain referral $(37.4 \%)$, and $124(60.2 \%)$ through advertising in the gay press in Melbourne, Australia. ${ }^{4}$

\section{Data collection}

The men completed an interviewer administered survey which took 60-90 minutes.

\section{Measures}

The interview included information on the men's county of birth, education, employment status, income, HIV status, and sexual history. The number of sexual partners in the previous year was assessed as the number of men with whom they had had anal sex, the number of additional men with whom they had had oral but not anal sex, and the number of men with whom they had had manual sex but not anal or oral sex. ${ }^{5}$ Partner numbers were measured as: none, 1, 2-5, 6-10, 1120, and more than 20 .

Social networks were enumerated as two distinct components, both of which were framed with regard to ongoing and/or intense relationships. The reporting about such relationships is known to be more valid and reliable than reporting about other relationships or specific interaction. ${ }^{6}$ The types of people participants named included sexual partners, friends, siblings and other family members. Firstly, participants were asked about the people they were closest to "that is, the people that you see or talk to regularly and share your personal thoughts and feelings with." For people in this category, participants reported the mix of men and women (men only; more men than women; equal men and women; more women than men; women only), the mix of straight and homosexual (only homosexual close friends; more homosexual friends, but some straight; equal homosexual and straight; more straight friends, but some homosexual; only straight close friends) and the mix of HIV positive and HIV negative (positive friends only; more positive than negative; equal positive and negative; more negative than positive; negative friends only). The second component was

Abbreviations: IDU, injecting drug users; MSM, men who have sex with men 
"people who seek out and spend time with on a regular basis, but who are not very close to you." For people in this category, participants reported the mix of men and women, the mix of straight and homosexual, and the mix of HIV positive and HIV negative. The age of all of the friends relative to the respondent (generally younger than me; about the same age as me; generally older than me) was also ascertained. For the purposes of the present paper, the two components were combined and summarised. Thus, the networks were coded as being majority homosexual if the respondent had indicated that the majority of people in both network components were homosexual. Summary measures for the gender mix and HIV mix were similarly derived.

Participants named up to 20 people in each of the two network components. Participants indicated which of those people named knew each other. Social network size was defined as the total number of individuals named plus the participant and network density as the proportion of people named who knew each other. For example, if a participant named five people, the network size was six. In a network of six individuals, there are 15 potential relationships. If all of those relationships was observed-that is, if every person knew every other person, network density would be 1.0. Given that the participant had named the five people the minimum possible network density was 0.20 because five of the 15 potential relationships had already been observed. ${ }^{6}$

\section{Analysis}

Analysis of variance was used to assess the relations between the participants' characteristics and the size and density of their networks.

Ordered logistic regression was used to evaluate the relations between the number of anal, oral, and manual sex partners in the previous year and the participants' and network characteristics. ${ }^{7}$ The implementation of ordered logistic regression was based on the proportional odds model which for each independent variable estimates a single parameter to describe the relation between each pair of ordered categories (that is, a single odds ratio is estimated to describe the observed relation between the independent variable and reporting 1 versus no partners, $2-5$ versus 1 , $6-10$ versus $2-5,11-20$ versus $6-10$, and $21+$ versus $11-20 .^{78}$ Thus, the reported odds ratios relate to reporting a particular

Table 1 Univariate odds ratios from ordered logistic regressions of the number of anal sex partners, the number of additional oral sex partners and the number of additional manual sex partners in the previous year

\begin{tabular}{|c|c|c|c|}
\hline & Anal sex & Oral sex & Manual sex \\
\hline & Odds ratio $(95 \% \mathrm{Cl})$ & Odds ratio $(95 \% \mathrm{Cl})$ & Odds ratio $(95 \% \mathrm{Cl})$ \\
\hline \multicolumn{4}{|l|}{ Characteristics of the men } \\
\hline \multicolumn{4}{|l|}{ Country of birth } \\
\hline Australia & - & - & - \\
\hline Other & $0.87(0.48$ to 1.58$)$ & $0.79(0.44$ to 1.43$)$ & 1.06 (0.59 to 1.94$)$ \\
\hline \multicolumn{4}{|l|}{ Education } \\
\hline Primary/secondary school/trade & - & - & - \\
\hline College/university & $0.77(0.47$ to 1.26$)$ & $1.07(0.65$ to 1.76$)$ & $1.16(0.70$ to 1.94$)$ \\
\hline \multicolumn{4}{|l|}{ Work status } \\
\hline Full time employment & - & - & - \\
\hline Part time employment & 1.34 (0.72 to 2.49$)$ & 1.10 (0.60 to 2.03$)$ & 1.57 (0.84 to 2.92$)$ \\
\hline Other & $0.66(0.38$ to 1.17$)$ & 0.58 (0.32 to 1.02$)$ & $0.67(0.36$ to 1.20$)$ \\
\hline \multicolumn{4}{|l|}{ Income } \\
\hline Up to $\$ 20000$ & - & - & - \\
\hline$\$ 20001-\$ 52000$ & 1.29 (0.75 to 2.22$)$ & $1.55(0.90$ to 2.67$)$ & 1.21 (0.69 to 2.10$)$ \\
\hline$\$ 52001+$ & 0.93 (0.47 to 1.82$)$ & $1.07(0.54$ to 2.10$)$ & $1.15(0.57$ to 2.29$)$ \\
\hline Age & 0.99 (0.97 to 1.01$)$ & 0.99 (0.97 to 1.01$)$ & 1.02 (1.002 to 1.044$)$ \\
\hline \multicolumn{4}{|l|}{ Sexual identity } \\
\hline Homosexual & - & - & - \\
\hline Bisexual/queer/other & $1.53(0.66$ to 3.6$)$ & $1.10(0.46$ to 2.68$)$ & $1.06(0.43$ to 2.61$)$ \\
\hline \multicolumn{4}{|l|}{ Lives with partner } \\
\hline No & - & - & - \\
\hline Yes & $0.48(0.27$ to 0.87$)$ & $0.92(0.52$ to 1.63$)$ & $1.02(0.56$ to 1.85$)$ \\
\hline \multicolumn{4}{|l|}{ HIV status } \\
\hline Negative & - & - & - \\
\hline Positive & 1.21 (0.62 to 2.37$)$ & 0.68 (0.33 to 1.38$)$ & $0.43(0.21$ to 0.92$)$ \\
\hline Unknown & 0.37 (0.17 to 0.82$)$ & $0.52(0.25$ to 1.10$)$ & $0.31(0.13$ to 0.74$)$ \\
\hline \multicolumn{4}{|l|}{ IDU history } \\
\hline Never & - & - & - \\
\hline Ever, but not in last year & 1.75 (0.78 to 3.93$)$ & 1.84 (0.75 to 4.49$)$ & 1.78 (0.76 to 4.13 ) \\
\hline In last year & 4.07 (1.64 to 10.07$)$ & $1.17(0.48$ to 2.87$)$ & $0.26(0.08$ to 0.82$)$ \\
\hline \multicolumn{4}{|l|}{ Characteristics of the networks } \\
\hline Egocentric network size & 1.05 (1.02 to 1.09 ) & 1.08 (1.04 to 1.12$)$ & 1.07 (1.03 to 1.11$)$ \\
\hline Egocentric network density & $0.16(0.003$ to 0.09$)$ & $0.014(0.002$ to 0.078$)$ & $0.050(0.008$ to 0.303$)$ \\
\hline \multicolumn{4}{|l|}{ Sexuality mix } \\
\hline Majority not homosexual & - & - & - \\
\hline Majority homosexual & $1.39(0.84$ to 2.31$)$ & $1.03(0.62$ to 1.71$)$ & 1.08 (0.64 to 1.80 ) \\
\hline \multicolumn{4}{|l|}{ Sex mix } \\
\hline Majority not male & - & - & - \\
\hline Majority male & $0.91(0.56$ to 1.50$)$ & 0.95 (0.58 to 1.54$)$ & 1.35 (0.82 to 2.23 ) \\
\hline \multicolumn{4}{|l|}{ Age mix } \\
\hline Generally younger & 1.06 (0.54 to 2.07$)$ & $0.79(0.40$ to 1.57$)$ & 1.49 (0.77 to 2.92$)$ \\
\hline Same age & - & - & - \\
\hline Generally older & 1.61 (0.88 to 2.93$)$ & 1.09 (0.62 to 1.93$)$ & $0.97(0.53$ to 1.76$)$ \\
\hline \multicolumn{4}{|l|}{ HIV status mix } \\
\hline Negative only & - & - & - \\
\hline Not negative only & 1.71 (1.03 to 2.83$)$ & 1.52 (0.93 to 2.51$)$ & $1.17(0.70$ to 1.97$)$ \\
\hline
\end{tabular}


category of sexual partners versus reporting the category of sexual partners directly beneath it.

Univariate models were run and those variables significant at 0.05 for each outcome were entered into a single model simultaneously. The least significant variable was removed and the model re-estimated until only significant variables remained.

While nearly $40 \%$ of the participants were recruited through chain referral, and hence were drawn from social networks that included at least one other participant, the observations were treated as independent in the analysis.

\section{Ethics}

The study was approved by the La Trobe University human ethics committee.

\section{RESULTS}

\section{Characteristics of the sample}

Of the 206 men in the study, most were Australian born $(79.1 \%)$, college or university educated $(60.2 \%)$, and identified as homosexual $(90.8 \%)$. Their mean age was 37.1 years (range 19-76). Most were in full time $(46.1 \%)$ or part time (23.3\%) employment and had an annual income of between \$20 001-\$52000 (€11 476-€29 836) (44.2\%), or more than $\$ 52000$ (€29 836) (18.9\%). Most were HIV negative (73.8\%) with fewer being HIV positive (15.5\%) or of unknown status $(10.7 \%)$. Most did not have a history of injecting drug use $(83.5 \%)$ and of those that did, more reported no injecting drug use in the last year $(8.4 \%)$ than in the year before that $(7.8 \%)$. Few men $(20.9 \%)$ lived with a partner. In the year before interview $15.0 \%$ of men reported no anal sex partners, $23.8 \%$ reported $1,27.7 \% 2-5,10.7 \% 6-10,8.7 \% 11-21$, and $14.1 \%$ more than 20. They also reported the number of additional partners with whom they had oral sex but not anal sex; $16.5 \%$ none, $10.7 \% 1,22.8 \% 2-5,12.6 \% 6-10,13.6 \% 11-$ 20 , and $23.8 \%$ more than 20 . Similarly, they reported the number of additional partners with whom they had manual sexual contact but neither anal nor oral sex; $43.7 \%$ none, $9.2 \% 1,10.2 \% 2-5,15.0 \% 6-10,9.7 \% 11-20$, and $12.1 \%$ more than 20. Strong positive correlations existed between the numbers of anal, oral, and manual sex partners reported.

Nearly half the men's networks contained a majority of men $(41.3 \%)$ and fewer were majority homosexual rather than straight $(36.9 \%)$ or entirely HIV negative $(36.9 \%)$. Most were generally the same age $(60.2 \%)$ rather than younger $(16.5 \%)$ or older $(23.3 \%)$ than the participant.

Network size had a mean of 18.5 (range 2-40) and network density a mean of 0.38 (range 0.06-1.00). Network size and network density were negatively correlated $(r=-0.35$, $\mathrm{p}<0.001$ ) as would be expected given that the larger the network the less likely it would be for every person in the network to know every other person in the network. Whether or not the men were recruited through chain referral was not significantly associated with network size or network density. Network density was unrelated to participants' characteristics or their networks except for income and whether the participant lived their partner. Density was higher among those with low $(0.42)$ or high $(0.38)$ rather than intermediate (0.35) incomes $(p=0.027)$. Those that lived with a partner had a higher network density than those who did not $(0.43$ versus $0.37, p=0.039)$. Network size was related to work status $(\mathrm{p}<0.001)$, income $(\mathrm{p}<0.001)$, and HIV status $(p=0.028)$. Network size was higher among those who worked full time (20.1) or part time (19.3) than those with another work status (15.5) and increased with income. Network size was lower among the men who were HIV positive (15.5) than those who were HIV negative (19.0) or whose status was unknown (18.9).

\section{Univariate models}

In univariate models, the likelihood of reporting a higher number of anal sex partners in the previous year was less if the participant lived with a partner or was of unknown HIV status rather than HIV negative (table 1). It was greater if the participant had injected drugs in the past year rather than never having injected and increased with network size. The likelihood of reporting a higher number of anal sex partners was negatively associated with network density. Having a network that was not exclusively HIV negative was associated with reporting higher numbers of anal sex partners. The number of additional reported oral sex partners was associated with increasing network size and decreasing network density. The number of additional manual sex partners increased with the participant's age, decreased if the participant was either HIV positive or of unknown HIV status, decreased if the participant had injected drugs in the past year rather than never having injected, increased with network size and decreased with network density.

\section{Multivariate models}

In the multivariate model the number of anal sex partners was higher if the participant had injected drugs in the past year rather than never having injected (odds ratio, 95\% confidence interval: $3.23,1.28$ to 8.15$)$, decreased with network density $(0.014,0.002$ to 0.008$)$, and increased if the network did not comprise only HIV negative people (1.77, 1.05 to 2.99). The model of additional oral sex partners contained network size (1.06, 1.02 to 1.10 ) and network density $(0.034,0.006$ to 0.205$)$. In addition to network size (1.05, 1.01 to 1.09$)$ and network density $(0.086,0.013$ to 0.563 ) the model for the number of additional manual sex partners also included age (1.03, 1.01 to 1.05$)$.

\section{DISCUSSION}

Social network composition and structure have previously been shown to be associated with HIV related communication, sexual behaviour and drug injection among drug users. ${ }^{12}$ Sexual network size has been shown to be associated with young homosexual men knowing someone with HIV and with AIDS. ${ }^{3}$ Here we have demonstrated that network characteristics are associated with MSM's sexual behaviour. Whether higher levels of sexual activity lead to the engagement with particular types of networks or whether those networks lead to particular forms of sexual activity is unclear. However, the strong relation between higher network density and lower levels of sexual activity is consistent with MSM being subject to significant surveillance by their peers-that is, being a member of a dense social network may result in more of your social (and sexual) activity being subject to scrutiny by your peers. This heightened scrutiny may act as a disincentive to engage in sexual activity with a large number of different sexual partners.

\section{Limitations}

The primary limitation of this study is the reliance on cross sectional data. Clearly, the relations between social network composition and structure and the social practices of individuals are highly dynamic and can only be captured through longitudinal studies. Crucially, without longitudinal studies we cannot be certain whether dense social networks constrain MSMs sexual behaviour or whether high levels of partner change make it difficult for MSM to maintain engagement in dense social networks. A potential limitation of the present study was to treat the observations as independent when some of the participants were drawn from overlapping social networks. That overlap may have served to reduce the variance observed in some of the 


\section{Key messages}

- The number of sexual partners that MSM have is strongly associated with the characteristics of their social networks

- Men with very dense social networks - that is, where most network members know most other network members, are the least likely to report large numbers of sexual partners

- Social networks of MSM may offer a novel target for explicit intervention for the prevention of HIV and other STIs

measures of network characteristics but the implications of this are entirely unclear.

\section{CONCLUSIONS}

We have demonstrated here, for the first time, strong associations between social network structure and the number of sexual partners report in the previous 12 months. The strength and consistency of these associations underline the importance of using network approaches to understanding the sexual behaviour of MSM and their potential value in identifying novel strategies for intervention.

\section{CONTRIBUTORS}

AMAS and JG conceived the study; AMAS, JG, DW, and PP designed the study; AMAS and DW analysed the data; all authors contributed to interpretation of the results and drafting the paper.

\section{Authors' affiliations}

A M A Smith, J Grierson, D Wain, M Pitts, Australian Research Centre in Sex, Health and Society, La Trobe University, 215 Franklin Street, Melbourne, Victoria 3000, Australia

P Pattison, Department of Psychology, University of Melbourne,

Melbourne, Victoria 3010, Australia

\section{REFERENCES}

1 Latkin C, Mandell W, Vlahov D, et al. People and places-behavioral settings and personal network characteristics as correlates of needle sharing. J Acquir Immune Defic Syndr 1996;13:273-80.

2 Latkin CA, Forman V, Knowlton A, et al. Norms, social networks and HIVrelated risk behaviours among urban disadvantaged drug users. Soc Sci Med 2003;56:465-76.

3 Morris M. Zavisca J, Dean L. Social and sexual networks: their role in the spread of HIV/AIDS among young gay men. AIDS Educ Prev 1995;7(Suppl):24-35.

4 Grierson J, Smith A, Wain D. Victorian networks study technical report. Melbourne: Australian Research Centre in Sex, Health and Society, 2003:28.

5 Grulich AE, de Visser RO, Smith AMA, et al. Sex in Australia: homosexual experience and recent homosexual encounters among a representative sample of adults. Aust N Z J Public Health 2003;27:155-63.

6 Wasserman S, Faust K. Social network analysis: methods and applications. Cambridge: Cambridge University Press, 1994.

7 StataCorp. Stata Statistical Software: Release 8. College Station, Texas: Stata Corporation, 2003.

8 Agresti A. Modelling ordered categorical data: recent advances and future challenges. Stat Med 1999;18:2191-201. 